\title{
From the outside in: The negative spillover effects of boundary spanners' relations with members of other organizations
}

\author{
LAKSHMI RAMARAJAN ${ }^{1}$, KATERINA BEZRUKOVA ${ }^{2 *}$, \\ KAREN A. JEHN ${ }^{3}$ AND MARTIN EUWEMA ${ }^{4}$ \\ ${ }^{1}$ Organizational Behavior Unit, Harvard Business School, Boston, Massachusetts, U.S.A. \\ ${ }^{2}$ Psychology Department, Santa Clara University, Santa Clara, California, U.S.A. \\ ${ }^{3}$ Department of Organisational Behaviour, Melbourne Business School, Carlton Victoria, Australia \\ ${ }^{4}$ Department of Psychology, Katholieke Universiteit Leuven, Leuven, Belgium
}

\begin{abstract}
Summary Contrary to much boundary spanning research, we examined the negative consequences of boundary spanning contact in multi-organizational contexts. Results from a sample of 833 Dutch peacekeepers show that employees' boundary spanning contact with members of other organizations was associated with reports of negative relationships with external parties (e.g., work-specific problems, culture-specific problems). These negative relationships also had a spillover effect such that they mediated the effect of boundary spanning contact on boundary spanners' negative attitudes toward their own jobs and organization (e.g., job attractiveness and confidence in the organization). Copyright (C) 2010 John Wiley \& Sons, Ltd.
\end{abstract}

Keywords: inter-organizational contact; boundary spanning; peacekeeping

\section{Introduction}

Inter-organizational contact has become a standard component of organizational life as employees become increasingly involved in frequent interactions across organizational boundaries (Cohn, 2000). For example, in rapidly changing scientific and technical fields, people from numerous organizations interact to advance knowledge (Liebeskind, Oliver, Zucker \& Brewer, 1996). In the public policy, social service, and non-profit sectors, people from multiple organizations come together to resolve complex social problems. In such multi-organizational settings, there are frequent calls for coordination and collaboration between employees across organizations (Jennings \& Ewalt, 1998). Thus, boundary spanning, or the linking of individuals within the organization to external parties (Adams, 1976; Friedman \& Polodny, 1992; Katz \& Kahn, 1978), has become an important aspect of many jobs. This raises an important question for organizations in multi-organizational settings: What is the impact of boundary spanning contact both on employees' relationships with members of other organizations and on their attitudes toward their own jobs and organization?

Early work on boundary spanning suggested that there were both positive and negative consequences of interorganizational boundary spanning contact in terms of relationships with members of other organizations (Adams, 1976; Tushman \& Katz, 1980). However, since then, research on the consequences of boundary spanning has largely documented its positive effects on external relationships, providing little attention to the possible negative consequences. For instance, activities such as searching for and collecting information and coordinating objectives, schedules, and resources across organizational boundaries (Adams, 1980; Edmondson, 1999) have been shown to

* Correspondence to: Katerina Bezrukova, Psychology Department, Santa Clara University, 500 El Camino Real, Santa Clara, CA 95053, U.S.A. E-mail: ybezrukova@scu.edu 
increase an organization's access to knowledge (Ancona \& Caldwell, 1992; Cross \& Cummings, 2004; Singh, 2005; Tushman, 1977), increase the level of trust placed in boundary spanners by members of other organizations (Perrone, Zaheer, \& McEvily, 2003), and extend the reach of an organization to diverse stakeholders (Ahearne, Bhattacharya, \& Gruen, 2005; Bartel, 2001). Richter and colleagues (Richter, West, Van Dick, \& Dawson, 2006) have documented the positive impact of boundary spanning interactions on intergroup relations and intergroup productivity. In contrast to this dominant view of positive consequences of boundary spanning contact, we argue that such contact in uncertain, multi-organizational settings can be detrimental. We draw upon social psychological research, which suggests that in certain situations intergroup contact can be an important source of intergroup conflict (Allport, 1954).

In addition to these external consequences (i.e., boundary spanning employees' relationships with members of other organizations), boundary spanning research has examined the internal consequences of boundary spanning contact (e.g., boundary spanners' attitudes toward their own jobs and organization, Blau, 1960; Marrone, Tesluk, \& Carson, 2007). However, much of this research has considered either internal or external consequences (e.g., Bartel, 2001; Callister \& Wall, 2001); hence, we know little about how these consequences may be related to one another or have potential spillover effects. For example, it is important for organizations to know if boundary spanners facing external problems are more likely to have negative attitudes toward the organization as well. In this study, we thus extend existing research on boundary spanning by explicitly examining the relationship between external relationships and internal attitudes toward one's own job and organization. We focus on boundary spanners' attitudes toward their jobs in terms of job attractiveness and attitudes toward their organization in terms of confidence in the organization. We draw upon research and theory on the spillover effects of conflict (Keenan \& Carnevale, 1989; LaBianca, Brass \& Gray, 1998; Smith, 1989) and the spillover effects people experience when they hold multiple social roles (Burke \& Stets, 2009; Edwards \& Rothbard, 2000) to understand how negative external consequences of boundary spanning contact may spill over into negative internal attitudes toward one's job and organization.

The context in which we investigate the links between boundary spanning contact in uncertain, multiorganizational settings and negative consequences for both external relations and internal attitudes is that of international peacekeeping. International peacekeeping is a situation in which many organizations, such as peacekeeping missions, local authorities and international organizations, are simultaneously trying to resolve a multi-faceted social problem, specifically the ending of large-scale political conflict. It is a complex and uncertain context in which members of these various organizations must interact with one another (Weiss, 1999). Thus, boundary spanning contact between members of different organizations such as peacekeepers, local government officials, and representatives of international organizations is a frequent occurrence. Furthermore, positive relationships with members of other organizations are important to creating a lasting and stable peace (Flint, 2001; Weiss, 1999). Unfortunately, in such complex or uncertain settings, where lack of coordination and differences in organizational goals abound, negative boundary spanning relationships seem to be common (Aall, 2000; Sion, 2008). Thus, our research context allows us to examine empirically the potential negative consequences of frequent boundary spanning contact in an uncertain, multi-organizational setting. Last, little is known in boundary spanning research about multinational environments (see Luo, 2005 for a recent exception). By specifically examining international peacekeeping, our research also informs knowledge of boundary spanning in international contexts.

\section{Negative Outcomes of Boundary Spanning Contact in Uncertain Contexts}

\section{External consequences: Work-specific and culture-specific problems with members of other organizations}

Frequent interpersonal contact across organizational boundaries may have negative consequences for boundary spanning employees' relationships with members of other organizations. We first examine work-specific problems, 
which we define as perceived discrepancies, disagreements or incompatibilities between one's own work-related interests and desires, and those of another party (Jehn \& Mannix, 2001; Wall \& Callister, 1995).

Unlike boundary spanning research, social psychological research on the contact hypothesis shows that, in the absence of certain optimal conditions - namely, equal status, common goals, intergroup cooperation, and the support of authorities, law or customs (Allport, 1954) — contact across group boundaries often results in problems and conflict with members of other groups (Gaertner et al., 1999; Hewstone \& Brown, 1986; Pettigrew, 1998; Pettigrew \& Tropp, 2006). Particularly in uncertain, multi-organizational settings, the conditions for optimal contact are not likely to be met. For instance, in multi-organizational settings, power and resources are often unequally distributed. As a result, individuals interacting across organizational boundaries often differ in status (Callister \& Wall, 2001). Furthermore, organizations in uncertain settings often lack common goals and institutional structures that facilitate positive work relationships across organizational boundaries (Beckman, Haunschild, \& Phillips, 2004; Haunschild \& Miner, 1997) (see the Research Context section for more details on the lack of optimal conditions for contact in our setting).

In addition to the lack of optimal conditions for contact across organizational boundaries, multi-organizational settings in which complex issues such as education, health care, or economic development are at stake are often characterized by limited resources (Anheier, Toepler \& Sokolowski, 1997; Bindu \& Lin, 2007; Mulroy \& Tamburo, 2004). Frequent contact with members of other groups under conditions of limited resources can also lead to workrelated problems because of perceptions that one's own group is more deprived than other groups (Brief, Umphress, Dietz, Burrows, Butz, \& Scholen, 2005; Harinck, De Dreu, \& Van Vianen, 2000; Pfeffer \& Salancik, 2003; Sherif \& Sherif, 1969). Thus, we predict that in uncertain, multi-organizational settings, the more frequently boundary spanning contact occurs, the more likely boundary spanners are to experience work-specific problems with members of other organizations (see Figure 1 for our conceptual model).

Hypothesis 1: The frequency of boundary spanners' contact with members of other organizations will be positively associated with work-specific problems with members of other organizations.

In addition to boundary spanners interacting with others as organizational representatives, in international settings, contact across organizational boundaries often overlaps with contact across national culture boundaries (Adler, 2000; Arnett, 2002; Erez \& Gati, 2004; Luo, 2005). With respect to our setting, one author on peacekeeping notes, "each national battalion brings its own particular cultural complex and set of assumptions" (Duffey, 2001: p. 147). As national culture is a framework for social interaction, guiding and motivating how individuals interact within a particular nation (Douglas \& Dubois, 1977; Hofstede, 2001; Schwartz, 1994, 1999), boundary spanning contact between people of different national cultures is another form of intergroup contact. The optimal conditions

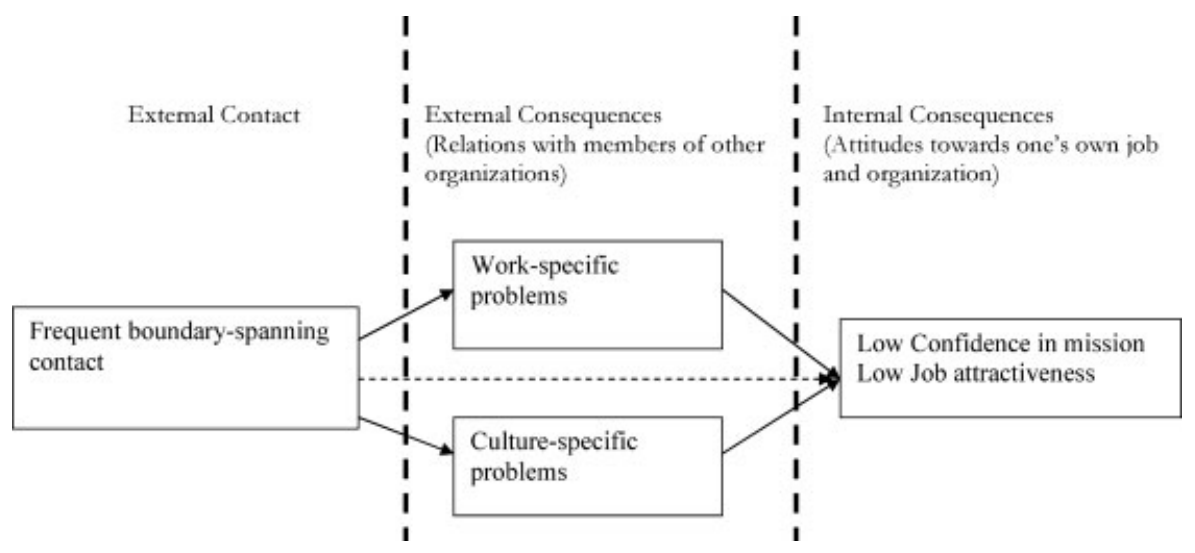

Figure 1. Conceptual model 
for contact across national cultures are also lacking in many international settings such as ours; thus, we predict frequent organizational boundary spanning contact will also lead to culture-specific problems (Allport, 1954; Hewstone \& Brown, 1986). We define culture-specific problems as perceived differences in expectations and opinions regarding appropriate behaviors and values in a cross-cultural interaction (Ayub \& Jehn, 2006; Brett \& Okumura, 1998; Dubinskas, 1992; Gelfand, Erez \& Aycan, 2007). For instance, in our setting, Dutch peacekeepers reported problems with Bosnians, Chinese, Africans and others, due to cultural differences in expectations and behaviors (see the Research Context and Measures sections for more details). Regarding the lack of optimal conditions for cultural contact in peacekeeping contexts, peacekeepers and residents do not share cultural goals; for example, peacekeepers see themselves as sojourners or cultural tourists, while the locals are long-term residents interested in rebuilding and revitalizing their country and culture (Sion, 2008). Members of the different national cultural groups also do not have equal status; peacekeepers from the developed countries often have more power and resources than locals or peacekeepers from developing countries (Duffey, 2001).

In addition to the lack of optimal conditions, cross-cultural contact also often involves emotional and behavioral adjustments to fit different national cultural expectations which often lead to culturally related problems (Molinsky, 2007). Although culture-specific problems typically fade as one gains experience or familiarity with a different culture (Bennett, 1986; Van Vianen, De Pater, Kristof-Brown, \& Johnson, 2004), in contexts such as ours, there are often many national cultures represented, making it difficult to gain familiarity and experience with all the different norms and expectations that one encounters. For example, in our data, Dutch peacekeepers mentioned the difficulties inherent in working with members of many different nationalities, each with their own set of expectations of appropriate conduct. Indeed, research shows that living in an environment with more than one national culture and engaging in frequent negotiations between sets of cultural values, norms, and identities can result in strained and stressful relationships (Romero, Carvajal, Valle, \& Orduna, 2007). Thus, we expect that in our setting, frequent boundary spanning contact will be positively associated with culture-specific problems.

Hypothesis 2: The frequency of boundary spanners' contact with members of other organizations will be positively associated with culture-specific problems with members of other organizations.

\section{Internal consequences: Job attractiveness and confidence in the organization}

Frequent interpersonal contact across organizational boundaries may also have negative consequences for employees' attitudes toward their own job and toward their organization. In our context, we examine attitudes toward one's job as job attractiveness and attitudes toward one's organization as confidence in the organization. Boundary spanning research shows that a high degree of interpersonal interaction can result in boundary spanners' negative attitudes toward their jobs (e.g., Singh, Goolsby \& Rhoads, 1994). This could be because employees involved in frequent interpersonal interaction often have to manage or suppress their own attitudes and emotions in order to perform their jobs (Brotheridge \& Grandey, 2002; Hochschild, 1983; Williams, 2007). This can be emotionally and psychologically demanding, which can then lead individuals to view their jobs as less attractive (Cordes \& Dougherty, 1993; Demerouti, Bakker, Nachreiner \& Schaufeli, 2001) and also to view the organization that puts them in such a situation with less confidence (Johnson \& O'Leary-Kelly, 2003).

Second, research on job attractiveness also highlights the importance of characteristics of the task environment in determining how attractive people may find their jobs and organizations (Rynes \& Miller, 1983; Saks, Wiesner \& Summers, 1996). In complex, multi-organization settings such as the one we examine, there are often insufficient resources to do one's job (Anheier et al., 1997; Bindu \& Lin, 2007; Mulroy \& Tamburo, 2004). In such circumstances, frequent contact across boundaries may highlight one's inability to work effectively as each

interaction reveals the constraints and limitations imposed on doing one's job, which can lead to low job attractiveness. Frequent contact may also decrease confidence in the organization because it raises concerns about the organization's ability to raise and provide the resources needed to accomplish its mission. Frequent contact 
across organizational boundaries in multi-organizational settings is also likely to highlight other difficult features of the task environment, such as complexity and uncertainty (Beckman et al., 2004; Jap, 2001), which may also result in boundary spanners doubting their organizations and regarding their jobs as unattractive. Therefore, we hypothesize:

Hypothesis 3: The frequency of boundary spanners' contact with members of other organizations will be negatively associated with job attractiveness and confidence in the organization.

\section{The spillover of external relations to internal attitudes}

While the above hypotheses suggest that boundary spanning contact can have a direct negative effect on relationships with outsiders and on attitudes toward the organization, contact can also indirectly have an effect on boundary spanners' attitudes toward their jobs and organization. Specifically, frequent contact can result in problems with those outside the organization which can then spillover to influence boundary spanners' attitudes toward their own jobs and organization. This can occur because boundary spanners have two major roles: Representing the organization to outsiders and integrating external information within the organization (Aldrich \& Herker, 1977; Friedman \& Polodny, 1992; Tushman \& Katz, 1980; Tushman \& Scanlan, 1981). Theory and research regarding multiple roles suggests that negative experiences in one role often spill over to influence negative attitudes in another role (Edwards \& Rothbard, 2000; Rothbard, 2001). Spillover may occur because negative experiences in one role, such as work-specific problems with members of other organizations, may lead to rumination or negative emotions, which then inhibit performance in another role, such as communicating within the organization (Burke \& Stets, 2009; Edwards \& Rothbard, 2000). Spillover could also occur because negative experiences in one role are distressing and tax individuals' psychological resources, thus resulting in withdrawal and disengagement from the other role (Greenhaus \& Beutell, 1985; Rothbard, 2001). For example, as we note above, because they have negative relationships with members of other organizations, boundary spanners may have decreased perceptions of personal accomplishment and performance in their external role (Cordes \& Dougherty, 1993), which can lead to negative attitudes in their role as members of their own organization.

Last, research on conflict dynamics shows that negative relationships in one domain, such as the intergroup domain, can be transported into negative relationships and attitudes in another domain, such as the within-group domain (Keenan \& Carnevale, 1989; Proudford \& Smith, 2003; Smith, 1989). This can occur because individuals themselves act as connections between different domains, facilitating the movement of conflict from one domain to another. For example, in our context, peacekeepers are trying to maintain peace along with the local governments and NGOs. While peacekeepers all represent the same organization when they are dealing with members of these outside organizations, once they are within their own organization they may each try to represent the point of view of their external counterpart, leading to conflicts between the peacekeepers themselves. That is, boundary-spanners' contact and subsequent conflict with those outside the organization may expose them to points of view that may cast their own jobs and organization in a negative light. In a similar vein, LaBianca et al. (1998) argued that in cooperative (vs. competitive) boundary-spanning contexts, conflict in one domain is likely to spillover to another domain. Therefore, we hypothesize:

Hypothesis 4: The frequency of boundary spanners' contact with members of other organizations will be negatively associated with job attractiveness and confidence in the organization, and this relationship will be mediated by their work-specific problems.

Culture-specific problems are also likely to mediate the effects of frequency of boundary spanning contact on attitudes toward one's job and organization. First, in international organizations, boundary spanners are typically interacting with members of a different culture due to their jobs and organization. In such circumstances, peacekeepers can attribute the fact that they are encountering culture-specific problems to their job and organization. 
Thus, external contact may indirectly influence negative attitudes toward one's job and organization through culturespecific problems. Negative experiences in the cross-cultural domain, a non-work domain, may also provoke negative thoughts and emotions which boundary spanners may carry back into the organization, a work domain. For example, a study of Japanese expatriates shows that cross-cultural adjustment in the non-work domain spills over into work-related attitudes (Takeuchi, Yun \& Tesluk, 2002). Furthermore, in our context, contact between members of local and foreign cultures is ideally occurring because they are engaged in building peace, not because they are in competition with one another. As noted above, when engaged in a non-competitive task, spillover effects between external and internal consequences of boundary spanning are more likely to occur (LaBianca et al., 1998). Thus, culture-specific problems with those outside the organization may be brought into the organization, resulting in negative attitudes toward one's own job and organization.

Hypothesis 5: The frequency of boundary spanners' contact with members of other organizations will be negatively associated with job attractiveness and confidence in the organization, and this relationship will be mediated by their culture-specific problems.

\section{Research Context}

The multi-organizational setting for our study of boundary spanning was an international peacekeeping mission. International peacekeeping missions are formed to inhibit violence between warring parties and to allow negotiated solutions in an ethnopolitical conflict situation. Peacekeeping missions are composed of peacekeeping forces or military troops contributed by countries that are third-parties to the ethnopolitical conflict. Peacekeeping forces have frequent contact with other organizations that are also involved in maintaining peace after a war (Aall, Miltenberg \& Weiss, 2003), such as local government officials, members of non-governmental organizations (NGOs, e.g., Oxfam or the Red Cross), and members of inter-governmental organizations (IGOs, e.g., UNICEF or UNHCR).

Positive relations between peacekeeping forces and these other organizations are crucial for effective peacekeeping (Flint, 2001; Weiss, 1999). However, despite this necessity, past research on ethnopolitical conflict suggests that there is a lack of optimal conditions for contact between peacekeeping forces and members of other organizations. First, there are definite status differences between the military and non-military actors (such as civilians or local government). Military peacekeeping organizations are often much larger and have access to greater physical and financial resources than NGOs and local governments of post-war countries; these often lead to status differences between military peacekeepers and NGOs (Aall, 2000: p. 133). Second, in the post-war context, "military actors clash with civilians over basic questions of means and ends of their mission based on differing conceptions of the mandate" (Duffey, 2001: p. 149). Often, military peacekeepers are engaged in short-term goals, such as stopping violence, while civilian actors are often engaged in more long-term goals, such as reconstruction (Aall, 2000: p. 134). Third, cooperation between peacekeeping forces and other actors in post-conflict situations is absent. For instance, during the Bosnian peacekeeping mission, the absence of cooperation between UN bodies, national peacekeeping forces, and local bodies was legendary (Cockell, 2002: p. 490). Finally, there are few regulative norms or institutionalized structures such as alliances or joint governance structures that support interorganizational contact (Aall, 2000; Last, 2000).

Reports and research on peacekeeping operations have also documented a wide variety of problems between members of different organizations involved in ethnopolitical conflict sites (Aall, 2000; Ramarajan, Bezrukova, Jehn, Euwema \& Kop, 2004; Report of the Panel on United Nations Peace Operations, 2000). The quote below from our data provides an illustration from a peacekeeper of boundary-spanning contact and the kinds of problems that are encountered in our context: 
I was stationed in a small town in Bosnia. There were rumors of bad treatment of prisoners in the local police station. From our UN-IPTF team we were trying to build a relationship of trust and confidence with the chief of this local police station. An NGO concerned with human rights came and demanded we should investigate these rumors immediately, passing by the local commander. This would violate our relationship, and we refused. The NGO made threats to report and bring this into the media.

For all these reasons, we believe that our research context is appropriate for testing our hypotheses.

\section{Method}

\section{Sample}

The participants were a sample of Dutch military peacekeepers stationed in one region who had participated in peacekeeping missions between 1995 and $1999(N=833)$. A survey methodology was employed to investigate the problems in peacekeepers' interactions during missions. The questionnaire was developed by the Clingendael Institute for International Relations with help from professional military staff. A copy of the questionnaire was sent to the home address of 1703 Dutch military peacekeepers from Fall 1999-Summer 2000. Anonymity was assured by assigning a third party (a group of university researchers) to process and analyze the data at an aggregate level. The response rate was 52 per cent, which is considered adequate in survey research, where the return rate of mail-in questionnaires is often 20-25 per cent (Roth \& BeVier, 1998). Interviews with UN-NATO officials indicated that the sample was comparable to the population of peacekeepers in terms of age, profession, experience, task demands, etc., suggesting no evidence of non-response bias (see Gibson \& Gibbs, 2006 for a similar procedure). We received permission to publish the data from the Clingendael Institute and the relevant Dutch authorities. The peacekeepers were all male and between the ages of 23 and 58 (mean age was 41 years). Their military rank ranged from Sergeant to General, with 25 per cent of the respondents holding the rank of Captains and 20 per cent holding the rank of Majors. They had served in the military between 2 years to 39 years, with a mean of 20 years. Lastly, the sample included land-forces ( 55 per cent), naval forces ( 3 per cent), air-forces ( 4 per cent), and the military police (38 per cent). There were no significant differences across these groups on the variables of interest.

\section{Independent Variable}

\section{Measures}

\section{Contact}

Since we were interested in all instances of employees' inter-organizational contact, we operationalized this variable as frequency of boundary-spanning contact between peacekeepers and members of other organizations such as NGOs, inter-governmental organizations, and local authorities. Prior literature on peacekeeping describes interactions with all three types of organizations as typical (Aall, 2000; Last, 2000). Participants responded to the question, "What parties did you have contact with? Please indicate the frequency of these contacts for your job." Three choices of parties were listed under this question, "Contact with NGOs (for example The Red Cross); Contact with local (or regional) authorities; Contact with Governmental Organizations (e.g., UNHCR)." Frequency of contact was measured on a five-point Likert scale $(1=$ hardly ever; $5=$ daily $)$ for each item, and the items were averaged to create the scale for contact (Cronbach's alpha was 0.73). 


\section{Dependent Variables}

We used two variables to operationalize employee external relations with members of other organizations: One was work-specific problems and the other was culture-specific problems. We also used two variables - job attractiveness and confidence in the organization - to operationalize employees' internal attitudes toward their own job and organization. We measured the various dependent variables using multiple methods.

\section{Quantitative measures}

\section{Work-specific problems}

Work-specific problems with members of other organizations was measured quantitatively using two survey items. Participants were first instructed to consider the problems they faced with a list of parties, including local authorities, IGOs, and NGOs. They were then asked to respond to the following items: "How serious were these problems with [local authorities/NGOs/IGOs]?" ( $1=$ not at all serious; $5=$ very serious $)$ and "Have you been personally involved in these problems with [local authorities/NGOs/IGOs]?" ( $1=$ not at all; $5=$ heavily involved). Conceptually, seriousness and personal involvement both reflect the intensity of the problem, i.e., both serious problems and problems one is personally involved in are likely to be highly intense work-specific problems. Therefore, we averaged the two scores (Cronbach's alpha $=0.80$ ) to arrive at our composite measure of workspecific problems.

In addition to the survey items, we used supplementary textual information that was available in our dataset to verify the nature and extent of work-specific problems faced by our participants. Some examples of boundary spanning interactions that participants described, which we coded as work-specific problems include: "Nongovernment organizations don't follow up on agreement," "I found the lack of willingness to cooperate within and between NGOs," and "the attitude of local authorities with whom we had to cooperate. They promise a lot but do little and protract the case until you leave." This supplementary information was collected from interviews that we conducted on a randomly selected sub-set of peacekeepers during the study. Even though these data were not sufficient to perform a full-scale content analysis of peacekeepers' experiences regarding their issues with personnel of other organizations, we were able to use the data to provide face validity for our measure.

\section{Confidence in organization (mission)}

This variable was measured with the survey item, "How much confidence did you have in the mission organization (UN-HQ, NATO)?" ( $1=$ No confidence; $5=$ Great confidence). In peacekeeping missions, confidence in the mission is akin to the extent of an employee's confidence in their organization.

\section{Qualitative measures}

In addition to the above survey items, we also had qualitative data from open-ended questions (all 833 participants provided answers). We content-analyzed these data to measure the two remaining dependent variables - "culturespecific problems" and "job attractiveness." We employed the content-analysis procedure that allowed us to make direct quantitative comparisons of peacekeepers' responses based on a replicable methodology (Huff, 1990; Kabanoff, 1996) frequently employed in prior research (e.g., Abrahamson \& Hambrick, 1997; Doucet \& Jehn, 1997; Kabanoff, 1997). First, we employed conventional translation and back-translation of the participants' responses (Brislin, 1980) which was done by two Dutch bilingual graduate research assistants independently 
(reliability $=97$ per cent). We then gave the English and Dutch versions of the transcripts to a Dutch bilingual academic (a professor of translation) to check whether the English version had achieved accuracy. All transcripts were found accurate.

Second, following the procedure of Doucet and Jehn (1997), we used the program MonoConc Pro 2.0 (Barlow, 2000) to create a frequency list with the terms mentioned most to least often. Then, two independent raters blind to the hypotheses independently considered all terms from this frequency list and developed lists of key words characterizing our variables of interest based on relevant job attraction research (Chapman, Uggerslev, Carroll, Piasentin, \& Jones, 2005; Dalal \& Singh, 1986; Rynes \& Barber, 1990; Saks, 1989; Saks et al., 1996) and literature on cross-cultural conflict (Adler, 2000; Ayub \& Jehn, 2006; Dubinskas, 1992). We controlled for method biases (e.g., the effects of consistency motifs, implicit theories, social desirability tendencies, dispositional and transient mood states, etc.) through the design of the study's procedures - different raters coded different variables (see Podsakoff, MacKenzie, Lee, \& Podsakoff, 2003: p. 887, for the "procedural remedies"). They discussed their respective lists of key terms and composed the final keyword list containing only the words that they agreed upon. For example, some key words for the "culture-specific problems" variable that cued us to search for text regarding instances of this variable for context coding were "cultural differences," "different countries," "multinational," "non-western colleagues," "different cultures," "foreign colleagues," "racial/cultural hatred." Examples of keywords for the "attractiveness of assignments" variable (reverse coded) are "treated like enemy," "unsafe/attacked/violence/ hostage," "death/dead," "abandoned," "not capable," “crisis," "threat," "suffering," "no hope/little hope/ hopelessness," "misery."

Then, following the method of Jehn and Werner (1993), two independent raters blind to the hypotheses conducted keyword searches on all individual responses, reviewed the surrounding context, and coded the text for each variable of interest based on the definitions of variables that they were given. They jointly went through the first few individual responses to develop the coding guidelines (e.g., "Any statements with reference to nation will be considered as a cultural statement"). They segmented roughly 30 per cent of all the data together with high reliability (the Cohen's Kappas were 0.73 and 0.78 for "culture-specific problems" and "job attractiveness," respectively). Then, they divided in half the remaining data and coded the data for job attraction or culture-specific problems. The rating scale for culture-specific problems was $1=$ not very culturally problematic to $5=$ very culturally problematic and for job attractiveness was $1=$ very unattractive to $5=$ very attractive. When raters rated a response farther than 1 point apart, they discussed the response until they reached an agreement and then, refined their coding rules.

\section{Culture-specific problems}

Based on research on cross-cultural interactions and conflict (Ayub \& Jehn, 2006; Brett \& Okumura, 1998; Jehn \& Bezrukova, 2004; Molinsky, 2007; Romero et al., 2007) we defined problems which arise due to perceptions of crosscultural differences as culture-specific problems. Individuals were asked the following question: "When people work together, it is inevitable that differences in opinion and vision, different interests and personal irritations occur. What problems in cooperation were most difficult during your latest mission?" Illustrative examples demonstrating culture-specific problems (rating of 5, very culturally problematic) identified from the data are provided below.

Problems arising from cultural differences are most difficult. Some examples are an attempt of suicide after a mutual disagreement and emotional eruptions during the daily evaluations.

Racial hatred between African colleagues from different countries was the most difficult problem to resolve. Other problems include tribal hatred between Africans from the same countries and irritations between Pakistani and Indians and colleagues from Bangladesh and Pakistan.

Working with Chinese always results in dangerous surprises. They are not capable for their tasks, but if you criticize them a conflict is started quickly. 


\section{Job attractiveness}

Respondents were asked, "What aspects of the assignments did you find attractive/unattractive?" Some examples of the participants' responses (rating $=1$, very unattractive) identified from the content-analyzed data are included below (the keywords that helped us find these instances are bolded):

It is hard to accept bureaucracy, hard to cope with deaths and being severely ill/hurt, hard to get used to intimidation, threat, and hostage taking.

I hate being subordinate to headquarters, feeling not capable; being left to your fate by the crisis. We fall back on UN that isn't there when you need them most.

\section{Control Variables}

We included age and military education as control variables because they reflect competence and expertise that may affect peacekeepers' perception of their conflicts with members of other organizations. We initially controlled for prior experience in the military, but since this variable was highly correlated with age $(r=0.78, p<0.001)$, we removed prior experience in the military from further analysis. We also controlled for hours that peacekeepers worked on average per week during their mission.

\section{Results}

We conducted a confirmatory factor analysis (CFA) of our variables using Mplus (Muthén \& Muthén, 1998) to test the underlying structure of our proposed model (Fabrigar, Wegener, MacCallum, \& Strahan, 1999; Podsakoff et al., 2003). We report the comparative fit index (CFI), standardized root mean square residual (SRMR), and the rootmean-square error of approximation (RMSEA). Employing Hu \& Bentler (1999) empirically derived joint criteria, model fit is good when CFI $>0.96$ and SRMR $<0.09$ or SRMR $<0.09$ and RMSEA $<0.06$. The measurement model proposed a three-factor structure corresponding to the hypothesized distinctions between contact, external relations and internal attitudes. The results indicate that the three-factor model fits the data well $\left(X^{2}=7.15, d f=3\right.$, $p=$ n.s.; $\mathrm{CFI}=0.98, \mathrm{RMSEA}=0.04$, and $\mathrm{SRMR}=0.02$ ). By comparison, the model positing that there was a single factor underlying all the study variables did not fit well $\left(X^{2}=33.07, d f=6, p<0.001 ; \mathrm{CFI}=0.89\right.$, RMSEA $=0.07$, and SRMR = 0.05). Further, because all measures were assessed through self-report, in order to control for the effects of common method variance, we also included a latent method factor as the fourth factor and allowed all items to load on their theoretical constructs as well as on the method factor. This approach is recommended as one of the preferred approaches to control for common method bias when the specific source of the method effects is unknown (Podsakoff et al., 2003). Adding the method factor did not improve model fit: The four-factor model fit the data poorly $(\mathrm{CFI}=0.86, \mathrm{RMSEA}=0.09$, and $\mathrm{SRMR}=0.07)$. This result further indicated the absence of severe common method variance.

Table 1 provides the means, standard deviations, and correlations between variables. Boundary spanners' contact with others from outside was positively and significantly correlated with work-specific problems and culture-specific problems, while it was negatively and significantly associated with attractiveness of the assignment and confidence in the organization's mission.

We then conducted hierarchical linear regression analysis to examine the direct and mediated effects of frequency of boundary spanning contact on negative attitudes toward relations with others and toward the job and organization. 
Table 1. Means, standard deviations, and correlations between variables

\begin{tabular}{|c|c|c|c|c|c|c|c|c|c|}
\hline & Mean & SD & & & & & & & \\
\hline Correlations & $N=833$ & $N=833$ & 1 & 2 & 3 & 4 & 5 & 6 & 7 \\
\hline 1. Age & 41.08 & 7.86 & & & & & & & \\
\hline 2. Military Education & 3.58 & 1.32 & 0.03 & & & & & & \\
\hline 3. Work Hours & 71.08 & 25.34 & 0.07 & 0.03 & & & & & \\
\hline 4. Contact & 0 & 1.11 & $0.10^{* *}$ & -0.06 & 0.02 & & & & \\
\hline 5. Work-specific problems & 2.25 & .96 & $0.09^{*}$ & -0.01 & 0.06 & $0.47^{* *}$ & & & \\
\hline 6. Culture-specific problems & .53 & 1.08 & 0.07 & -0.01 & -0.01 & $0.14^{* *}$ & $0.11^{* *}$ & & \\
\hline 7. Confidence in Mission & 3.32 & 1.03 & $-0.09^{*}$ & $0.08^{*}$ & $0.08^{*}$ & $-0.12^{* *}$ & $-0.13^{* *}$ & $-0.13^{* *}$ & \\
\hline 8. Job Attractiveness & 3.00 & 0.72 & 0.00 & -0.02 & -0.06 & $-0.10^{* *}$ & $-0.19^{* *}$ & -0.04 & $-0.12^{* *}$ \\
\hline
\end{tabular}

${ }^{*} p<0.05 ;{ }^{* *} p<0.01$, two-tailed tests.

Hypotheses 1 and 2 predicted that boundary spanning employees would have more negative outcomes regarding relationships with those outside the organization, such as work-specific problems and culture-specific problems, when they had more frequent contact with others from outside their organization. As shown in Table 2, Column 1, the relationship between contact and work-specific problems was significant and positive $(\beta=0.44, p=0.00)$ and as shown in Table 3, Column 1, the relationship between contact and culture-specific problems was significant and positive $(\beta=0.14, p=0.00)$. Therefore, in support of Hypotheses 1 and 2 , we do find that frequent contact across organizational boundaries in complex, multi-organizational settings, such as ethnopolitical conflict interventions, is associated with negative attitudes regarding relationships with external parties.

Hypothesis 3 predicted that there will be a negative association between frequency of boundary spanning contact and boundary spanners' attitudes toward one's job and organization, specifically, their confidence in the organization and attraction to the job. As shown in Table 2, Column 2, the relationship between contact and confidence in the mission of the organization is negative $(\beta=-0.10, p=0.00)$ and as shown in Table 2, Column 3 , the relationship between contact and attractiveness of one's job is also negative $(\beta=-0.09, p=0.05)$. Thus, in support of

Table 2. Work-specific problems as a dependent variable and a mediator

\begin{tabular}{|c|c|c|c|c|c|}
\hline & Column 1 & Column 2 & Column 3 & Column 4 & Column 5 \\
\hline & $\begin{array}{c}\text { Work-specific } \\
\text { problems }\end{array}$ & $\begin{array}{l}\text { Confidence in } \\
\text { mission }\end{array}$ & $\begin{array}{c}\text { Job } \\
\text { attractiveness }\end{array}$ & $\begin{array}{l}\text { Confidence in } \\
\text { mission }\end{array}$ & $\begin{array}{c}\text { Job } \\
\text { attractiveness }\end{array}$ \\
\hline \multicolumn{6}{|l|}{ Step 1: Controls } \\
\hline Age & $0.08^{*}$ & $-0.09^{* *}$ & 0.00 & $-0.09^{* *}$ & 0.00 \\
\hline Work hours & 0.05 & $0.08^{*}$ & -0.05 & $0.08^{*}$ & -0.05 \\
\hline Military education & -0.01 & $0.07^{*}$ & -0.02 & $0.07^{*}$ & -0.02 \\
\hline$R^{2}$ & 0.01 & 0.02 & 0.00 & 0.02 & 0.00 \\
\hline Adjusted $R^{2}$ & 0.01 & 0.02 & 0.00 & 0.02 & 0.00 \\
\hline$F$ & $2.66^{*}$ & $5.60^{* *}$ & 0.79 & $5.60^{* *}$ & 0.79 \\
\hline \multicolumn{6}{|l|}{ Step 2: Main effects } \\
\hline Contact (Cnt) & $0.44^{* * *}$ & $-0.10^{* *}$ & $-0.09^{*}$ & -0.06 & -0.02 \\
\hline Work-specific problems & & & & $-0.09^{*}$ & $-0.16^{* *}$ \\
\hline Change in $R^{2}$ & 0.20 & 0.01 & 0.01 & 0.02 & 0.03 \\
\hline$F$ change & $201.97^{* * *}$ & $8.56^{* * *}$ & $6.98^{* *}$ & $7.34^{* *}$ & $12.30^{* * *}$ \\
\hline$R^{2}$ & 0.20 & 0.03 & 0.01 & 0.04 & 0.03 \\
\hline Adjusted $R^{2}$ & 0.20 & 0.03 & 0.01 & 0.03 & 0.03 \\
\hline$F$ & $52.97^{* * *}$ & $6.38^{* * *}$ & $2.34^{*}$ & $6.35^{* * *}$ & $5.41^{* * *}$ \\
\hline
\end{tabular}

${ }^{*} p<0.05 ;{ }^{* *} p<0.01$, two-tailed tests. 
Table 3. Culture-specific problems as a dependent variable and a mediator

\begin{tabular}{|c|c|c|c|c|c|}
\hline & Column 1 & Column 2 & Column 3 & Column 4 & Column 5 \\
\hline & $\begin{array}{l}\text { Culture-specific } \\
\text { problems }\end{array}$ & $\begin{array}{l}\text { Confidence in } \\
\text { mission }\end{array}$ & $\begin{array}{c}\text { Job } \\
\text { attractiveness }\end{array}$ & $\begin{array}{l}\text { Confidence in } \\
\text { mission }\end{array}$ & $\begin{array}{c}\text { Job } \\
\text { attractiveness }\end{array}$ \\
\hline \multicolumn{6}{|l|}{ Step 1: Controls } \\
\hline Age & 0.07 & $-0.09^{* *}$ & 0.00 & $-0.09^{* *}$ & 0.00 \\
\hline Work Hours & -0.02 & $0.08^{*}$ & -0.05 & $0.08^{*}$ & -0.05 \\
\hline Military Education & -0.01 & $0.07^{*}$ & -0.02 & $0.07^{*}$ & -0.02 \\
\hline$R^{2}$ & 0.01 & 0.02 & 0.00 & 0.02 & 0.00 \\
\hline Adjusted $R^{2}$ & 0.00 & 0.02 & 0.00 & 0.02 & 0.00 \\
\hline$F$ & 1.33 & $5.60^{* *}$ & 0.79 & $5.60^{* *}$ & 0.79 \\
\hline \multicolumn{6}{|l|}{ Step 2: Main effects } \\
\hline Contact $(\mathrm{Cnt})$ & $0.14^{* * *}$ & $-0.10^{* *}$ & $-0.09^{*}$ & $-0.08^{*}$ & $-0.09^{*}$ \\
\hline Culture-specific problems & & & & $-0.11^{* *}$ & -0.03 \\
\hline Change in $R^{2}$ & 0.02 & 0.01 & 0.01 & 0.02 & 0.01 \\
\hline$F$ change & $15.31^{* * *}$ & $8.56^{* * *}$ & $6.98^{* *}$ & $9.10^{* * *}$ & $3.86^{*}$ \\
\hline$R^{2}$ & 0.02 & 0.03 & 0.01 & 0.04 & 0.01 \\
\hline Adjusted $R^{2}$ & 0.02 & 0.03 & 0.01 & 0.04 & 0.01 \\
\hline$F$ & $4.84^{* *}$ & $6.38^{* * *}$ & $2.34^{*}$ & $7.07^{* * *}$ & $2.03^{\dagger}$ \\
\hline
\end{tabular}

${ }^{\dagger} p<.1 ;{ }^{*} p<.05 ;{ }^{* *} p<.01$, two-tailed tests.

Hypothesis 3, we also find that boundary spanners' frequent contact across organizational boundaries in complex, multi-organizational settings is associated with negative attitudes toward their own jobs and organization.

Last, Hypotheses 4 and 5 stated that the relationship between frequency of contact and attitudes toward one's own job and organization will be mediated by negative relationships with those outside the organization. In Table 2 (Columns 2-5), we show the results of a mediated regression analysis for work-specific problems (H4), using Baron and Kenny's (1986) three-regression procedure. In Table 2, Column 2 and Column 3, as we noted above, we show that our independent variable, frequency of contact, significantly predicts our outcomes, confidence in the mission $\left(\beta_{\text {contact }}=-0.10, p<0.01\right)$ and job attractiveness $\left(\beta_{\text {contact }}=-0.09, p<0.05\right)$, respectively. However, as shown in Table 2, Column 4 , the effect of contact on confidence in the mission is no longer significant $\left(\beta_{\text {contact }}=-0.06\right.$, $p=0.12)$ when work-specific problems is added to the equation $\left(\beta_{\text {work-specific problems }}=-0.09, p<0.05\right)$ and the Sobel statistic is also significant $(t=-1.99, p=0.04)$. Similarly, as shown in Table 2, Column 5, the effect of contact on job attractiveness $\left(\beta_{\text {contact }}=-0.02, p=0.59\right)$ is no longer significant when work-specific problems is added to the equation ( $\beta_{\text {work-specific problems }}=-0.16, p=0.00$, and Sobel statistic is $t=-4.33, p<0.00$ ). Thus, we observe strong support for Hypothesis 4 that work-specific problems mediate the relationship between boundary spanning contact and attitudes toward the job and organization.

Regarding the influence of culture-specific problems as a mediator (H5), in Table 2, Column 2 and Column 3, we show that our independent variable, frequency of contact, significantly predicts our outcomes, confidence in the mission $\left(\beta_{\text {contact }}=-0.10, p<0.01\right)$ and job attractiveness $\left(\beta_{\text {contact }}=-0.09, p<0.05\right)$, respectively. However, as shown in Table 3 , Column 4 , the effect of contact on confidence in the mission remains significant $\left(\beta_{\text {contact }}=-0.08\right.$, $p<0.05)$ when culture-specific problems is added to the equation $\left(\beta_{\text {culture-specific problems }}=-0.11, p=0.00\right)$, but the Sobel statistic is also significant $(t=-2.64, p=0.01)$, suggesting partial mediation. Last, as shown in Table 3, Column 5, there is no support for the hypothesis that the relationship between contact and job attractiveness is mediated by culture-specific problems $\left(\beta_{\text {culture-specific problems }}=-0.03\right.$, n.s. $)$ and the Sobel statistic is also not significant. Thus, support for the role of culture-specific problems as a mediator (Hypothesis 5) is limited; culturespecific problems does not mediate the relationship between frequency of contact and job attractiveness but it does partially mediate the relationship between frequency of contact and confidence in the organization's mission.

We also confirmed our results of the mediation, that is, our spillover hypothesis, using structural equation modeling (SEM) (Muthén \& Muthén, 1998). We examined a model in which our two variables regarding 
problems with external parties (i.e., work-specific problems and culture-specific problems) were dependent variables, the independent variable was the frequency of contact and age, education and hours were control variables. Simultaneously, the two dependent variables regarding negative attitudes toward the job and organization (i.e., job attractiveness and confidence in the mission) were also included in the model and the independent variables were the frequency of contact, work-specific problems and culture-specific problems.

Model fit is seen as reasonable when $X^{2} / d f<3$ and CFI $>0.90$ (Jackson, Colquitt, Wesson \& Zapata-Phelan, 2006; Kline, 1998) or employing $\mathrm{Hu} \&$ Bentler (1999) empirically derived joint criteria, when CFI $>0.96$ and SRMR $<0.09$ or SRMR $<0.09$ and RMSEA $<0.06$. Our hypothesized model fit the data well: $X^{2}=18.16$, $p<=0.01, d f=7$, so $X^{2} / d f<3$ and CFI $=0.96$ and SRMR $=0.03$ and RMSEA $=0.04$. Furthermore, the estimates for the paths confirm the results we observed with the regression analyses; specifically: (a) Contact was positively and significantly associated with work-specific problems, $\beta=0.36, p<0.01$; (b) contact was positively and significantly associated with culture-specific problems, $\beta=0.14, p<0.01$; (c) work-specific problems was negatively and significantly associated with confidence in the organization's mission, $\beta=-0.09, p<0.05$; (d) workspecific problems was negatively and significantly associated with job attractiveness, $\beta=-0.11, p<0.05$; (e) culture-specific problems was negatively and significantly associated with confidence, $\beta=-0.10, p<0.05$; and (f) culture-specific problems was negatively but not significantly associated with job attractiveness, $\beta=-0.01$, n.s. Thus, our results showing strong support for four of our five hypotheses (H1-H4) and partial support for the fifth (H5) are consistent across both the regression and SEM approaches.

\section{Discussion}

Our theoretical and empirical findings enable us to make several contributions to the literature on boundary spanning. First, this paper extends existing research on boundary spanning by examining the negative outcomes of unregulated boundary spanning activity. Our results revealed that frequent contact of boundary spanning peacekeepers with other organizations' personnel was related to more problems (both work- and culture-related) faced with these external parties, and also related to more negative attitudes toward their own job and organization. Although our findings are consistent with research that demonstrates that negative biases toward members of the outgroup increase under conditions of uncertainty (Mullin \& Hogg, 1998; Reid \& Hogg, 2005), past boundary spanning research has primarily emphasized the positive outcomes of boundary spanning for organizations (Ahearne et al., 2005; Ancona \& Caldwell, 1992; Bartel, 2001; Cross \& Cummings, 2004; Perrone et al., 2003; Singh, 2005; Tushman, 1977). However, we argued that the negative outcomes of boundary spanning activity deserve attention in their own right, and so we examined a variety of negative outcomes related to both employees' relations with others and employees' responses to their job and organization.

Second, we study boundary spanners' attitudes toward their jobs and organization, and we find similarity in the direction of the effects of contact on internal attitudes and external relations. This also counters boundary spanning theory which suggests that boundary spanners' external relationships and internal attitudes are inversely relatedthat is, cooperative and positive relationships with outsiders may result in less positive attitudes within boundary spanners' own organization and vice versa (e.g., Bartel, 2001; Perrone et al., 2003). One reason for this difference could be that prior research did not examine boundary spanning contact in complex, uncertain, multi-organizational settings; rather they examined boundary spanning in situations where boundary spanning contact is likely to be facilitated (e.g., joint ventures, corporate-community alliances, etc.). It is possible that contexts such as ours are challenging task environments, resulting in difficult external relations and hence negative internal attitudes.

In fact, we proposed and found evidence to support such a "spillover" hypothesis to explain why both internal and external consequences may be negatively related to boundary spanning contact. While one possibility is that conflict between groups leads to cohesion within each group (e.g., Sherif \& Sherif, 1969), a spillover hypothesis suggests that 
conflict between groups may lead to conflict within groups (or vice versa) (e.g., Keenan \& Carnevale, 1989; Smith, 1989). Thus, in contrast to much boundary spanning research that emphasizes that internal attitudes and external relations are often opposites, we draw on research on conflict dynamics (e.g., Keenan \& Carnevale, 1989; Smith, 1989) and multiple role research (e.g., Burke \& Stets, 2009; Edwards \& Rothbard, 2000) to propose and test a spillover hypothesis. We show that indeed, in complex, multi-organizational settings, the negative effects of boundary spanning contact spillover from external relationships into attitudes toward one's job and organization. Thus, we provide a novel and more complete theoretical and empirical account of the far-reaching negative effects of boundary spanning contact, moving from outside the organization to within it.

Interestingly, we found that work-specific problems with outsiders spill over to negatively influence both confidence in one's organization and job attractiveness, but we do not find that culture-specific problems spill over as strongly. One reason for this could be that work-specific problems with members of other organizations could naturally affect attitudes related to work (such as one's job and organization), but culture-specific problems may be less easily attributed to aspects of work and more easily attributed to other factors (for instance, their own or the other party's personality or cross-cultural experience). Examining a wider range of internal attitudes might allow future research to hone in on the ways in which external culture-specific problems could spill over into organizations.

\section{Study Limitations and Future Research}

We realize that our study has several limitations. Primarily, our data collected based on survey methodology do not allow us to determine true cause-effect relationships which is common in field research. We believe that our study methodology, while lacking causal conclusions, has advantages in bringing to bear multiple methods (quantitative and qualitative data), a unique setting and sample in which to test our hypotheses, and complex and contextualized social perceptions (Huberman \& Miles, 1985). We also performed the mediation analyses in the reverse direction to check the robustness of our model and did not find support for that model. Past research on boundary spanning (Callister \& Wall, 2001; Kellogg, Orlikowski, \& Yates, 2006), peacekeeping (Duffey, 2001; Last, 2000; Sion, 2008), and the personal interview experiences of one of the authors at various times in the peacekeeping process, also suggest that our model is reasonable and feasible.

We have taken several strategies to address the common method issues that may emerge from our primary reliance on a single survey. We designed our coding procedure in line with Podsakoff and colleagues' (2003) guidelines (e.g., different raters who were unfamiliar to specific hypotheses performed the coding of different variables in our study) to eliminate the possibility for common variance due to method. We also performed SEM analyses to control for common method bias when the specific source of the method effects is unknown (Fabrigar et al., 1999; Podsakoff et al., 2003). Our results indicated the absence of severe common method variance. Finally, to provide external verification of our work-specific problems dependent variable, we incorporated additional peacekeepers' interviews and responses regarding the problems they have experienced with others from outside the organization in our analysis. The consistency of our findings across both the qualitative and quantitative measures gives us confidence in our data.

Our second set of limitations is related to our participants' responses. First, despite our satisfactory response rate of 52 per cent, we lack data on non-respondents, thus it is difficult to know if individuals who had negative boundary spanning experiences were also less likely to respond to our survey. However, our results were robust to some checks for non-response bias, such as modeling of selection bias and regression imputation methods (Heckman, 1979; Roth, 1994; Switzer III, Roth, \& Switzer, 1998). Our interviews with UN-NATO officials also alleviate some of our concerns about critical differences between our sample and the population of peacekeepers. Second, despite having been collected soon after the end of the mission, we realize our data may be subject to retrospective biases; that is, peacekeepers could be biased in recalling and hence over-reporting instances of conflict (Pratto \& John, 1991). 
However, recent research specifically on autobiographical memory suggests that for adaptive reasons people are more likely to remember positive events more than negative events (Walker, Skowronski, \& Thompson, 2003). Furthermore, the unpleasantness associated with negative events has been shown to fade in memory faster than the pleasantness associated with positive events (Walker, Vogl, \& Thompson, 1997), which would also make it harder to find support for our hypotheses.

Third, there is a possibility that peacekeepers belonging to the same unit had shared experiences of problems with external parties, yet we were not able to gather unit level information to test for hierarchical structures in our data. However, peacekeepers typically do not interact with others outside the organization as an entire unit; rather, most interactions involve two individuals from each organization. In fact, a unit often covers a large physical area (for example, estimates of the Dutch peacekeeping unit in Srebernica at the time of the massacre in 1995 was 500 peacekeepers covering an area of 200 sq. miles with a population of over 36000 people) making each interaction of a peacekeeper with local people or government and NGO employees truly unique. Last, some survey questions on employees" negative attitudes seem to assume there were problems (" $1=$ not at all serious" has both people who had no problems and those that had minimal problems). To address this concern, we removed the people with at least one " 1 " on any of the items that were used to create the "work-specific problems" scale and re-ran our analysiswe found similar results. However, future research should consider using better anchors for the questions to more accurately measure the variables of interest.

Finally, this study has some limitations and potential opportunities for future research in terms of the variables examined. Despite our discussion of the alignment of organizational and national cultural boundaries (Hypothesis 2) (Adler, 2000; Erez \& Gati, 2004), we do not have the data to examine the joint versus separate effects of the two types of boundary-crossing contact on problems. Future research could experimentally investigate this by assigning individuals from the same (vs. different) countries to represent the same (vs. different) groups and make contact across both boundaries. We also did not measure role conflict, a variable which has been examined in the boundary spanning literature (Adams, 1976; Friedman \& Polodny, 1992; Lysonski, Singer, \& Wilemon, 1988) and could also act as a mediator for our hypothesis regarding the influence of contact on negative internal consequences. Lastly, we were not able to empirically distinguish between types of conflict in our setting, such as resource versus identity conflicts (Harinck et al., 2000). While contact is likely to lead to both types of conflicts in our setting, studying contexts where such types of conflict can be separated is also a direction for future research.

\section{Practical Implications}

From a practical and managerial perspective, our sample and setting are particularly relevant in today's world of increasingly soft organizational boundaries and complex multi-organizational settings. We believe that studying the military, given current issues of world politics, will be informative to both researchers and policymakers. The state of affairs we describe is not only relevant to organizations operating in international political conflict, but also to a wide variety of other organizational fields and industries such as disaster management, health care, or biotechnology, where boundary spanners from multiple organizations operate in uncertain environments. For instance, research in biotechnology has shown that inter-organizational relations are usually carried out by individual scientists who may be from large pharmaceutical companies, universities, and small biotech firms, each of whom may come with differing expectations regarding collaborative work in technologically uncertain environments (Liebeskind et al., 1996; Oliver \& Liebeskind, 1998). In disaster response, government officials, local community leaders and private business owners are often forced to work together on short-notice in the absence of organizational mechanisms that support cooperation (Kunreuther \& Useem, 2009).

For managers of employees in boundary spanning roles, the contact conditions under which boundary spanning occurs in complex, multi-organizational settings should be taken into account. Our finding that greater contact 
between boundary spanners can increase conflict, rather than cooperation, in the absence of inter-organizational norms and routines about cooperation, also has implications for organizational strategy in multi-organizational settings. Organizational decision-makers in similar situations may want to analyze the implications of contactunder-uncertainty for both external and internal consequences when thinking about the costs of alliances, joint ventures, or other cooperative mechanisms. We hope this research will help contemporary organizations to recognize how complex, uncertain environments can affect boundary spanning activities, and to leverage their external interactions through cooperative mechanisms.

\section{Acknowledgements}

We would like to thank the University of Pennsylvania Research Foundation for financial support and the members of the M-squared group at the University of Pennsylvania for their comments on earlier drafts. We also thank the Dutch Ministry of Defense and the Clingendael Institute for their cooperation in this project. We are very grateful to Nicolien Kop, Richard de Ridder, Jaap Dijkstra, Richard van Eijsden, Kees Homan, Jan Rood, and Wendy Broesder for their important contributions to this project. We thank Nicole Gonzalez, Poonam Maharjan, Carlos Cavalie, Evelyn Nunez and Emily-LeRoux Rutledge for their research assistance.

\section{Author biographies}

Lakshmi Ramarajan is a Post-Doctoral Fellow in Organizational Behavior at Harvard Business School. Her research examines the management and consequences of multiple identities and group boundaries on intergroup conflict and cooperation in organizations.

Katerina Bezrukova is an Assistant Professor of Psychology at Santa Clara University. Her research interests include workplace diversity, organizational conflict and performance, intergroup and inter-organizational relations, and diversity training. Her work appears in Organization Science, Organizational Behavior and Human Decision Processes, Personnel Psychology, Journal of Organizational Behavior, and other outlets.

Karen A. Jehn is Professor of Organizational Behaviour in Melbourne Business School. Her research examines intragroup conflict, group composition and lying in organizations. She has authored numerous publications in these areas, including articles in the Academy of Management Journal, Administrative Science Quarterly, Journal of Personality and Social Psychology, Organization Science, Organization Behavior and Human Decision Processes and Journal of Business Ethics.

Martin C. Euwema is Professor for Organizational Psychology at Katholieke Universiteit, Leuven, Belgium. He received his doctorate from the Free University, Amsterdam, The Netherlands. His current research interests include leadership, conflict management, and organizational change.

\section{References}

Aall, P. (2000). NGOs, conflict management and peacekeeping. International Peacekeeping, 7, 121-141.

Aall, P., Miltenberg, D., \& Weiss, T. G. (2003). Guide to IGOs, NGOs, and the military in peace and relief operations. Washington, DC: United States Institute of Peace. 
Abrahamson, E., \& Hambrick, D. C. (1997). Attentional homogeneity in industries: The effect of discretion. Journal of Organizational Behavior, 18, 513-532.

Adams, J. S. (1976). The structure and dynamics of behaviour in organizational boundary roles. In M. D. Dunnette (Ed.), Handbook of industrial and organizational psychology (1175-1199). Chicago, IL: Rand McNally.

Adams, J. S. (1980). Interorganizational processes and organization boundary activities. In B. W. Staw, \& L. L. Cummings (Eds.), Research in Organizational Behavior (2, 321-355). Greenwich, CT: JAI Press.

Adler, N. J. (2000). International dimensions of organizational behavior (4th ed.). Cincinnati, OH: Southwestern.

Ahearne, M., Bhattacharya, C. B., \& Gruen, T. (2005). Antecedents and consequences of customer-company identification: Expanding the role of relationship marketing. Journal of Applied Psychology, 90, 574-585.

Aldrich, H., \& Herker, D. (1977). Boundary Spanning roles and Organization Structure. Academy of Management Review, 2, $217-$ 230.

Allport, G. W. (1954). The nature of prejudice. Reading, MA: Addison-Wesley.

Ancona, D., \& Caldwell, D. (1992). Bringing the boundary: External activity and performance in organizational teams. Administrative Science Quarterly, 37, 634-665.

Anheier, H. K., Toepler, S., \& Sokolowski, S. W. (1997). The implications of government funding for NPOs: Three proportions. International Journal of Public Sector Management, 10, 190-213.

Arnett, J. J. (2002). The psychology of globalization. American Psychologist, 57, 774-783.

Ayub, N., \& Jehn, K. A. (2006). National diversity and conflict in multinational workgroups: The moderating effect of nationalism. International Journal of Conflict Management, 17, 181-202.

Barlow, M. (2000). Concordancing with MonoConc Pro. 2.0. Athelstan.

Baron, R. M., \& Kenny, D. A. (1986). The moderator-mediator variable distinction in social psychological research: Conceptual, strategic, and statistical considerations. Journal of Personality and Social Psychology, 51, 1173-1182.

Bartel, C. A. (2001). Social comparisons in boundary-spanning work: Effects of community outreach on members' organizational identity and identification. Administrative Science Quarterly, 46, 379-414.

Beckman, C. M., Haunschild, P. R., \& Phillips, D. J. (2004). Friends or strangers? Firm-specific uncertainty, market uncertainty, and network partner selection. Organization Science, 15, 259-275.

Bennett, J. M. (1986). Modes of cross-cultural training: Conceptualizing cross-cultural training as education. Special issue: Theories and methods in cross-cultural orientation. International Journal of Intercultural Relations, 10, $117-134$.

Bindu, A., \& Lin, Z. (2007). Understanding collaboration outcomes from an extended resource-based view perspective: The roles of organizational characteristics, partner attributes, and network structures. Journal of Management, 33, 697-723.

Blau, P. M. (1960). Exchange and power in social life. New York, NY: Wiley.

Brett, J. M., \& Okumura, T. (1998). Inter- and intracultural negotiation: U.S. and Japanese negotiators. Academy of Management Journal, 41, 495-510.

Brief, A., Umphress, E., Dietz, J., Burrows, J., Butz, R., \& Scholen, L. (2005). Community matters: Realistic group conflict theory and the impact of diversity. Academy of Management Journal, 48, 830-844.

Brislin, R. W. (1980). Translation and content analysis of oral and written material. In H. C. Triandis, \& J. W. Berry (Eds.), Handbook of cross-cultural psychology, vol. 2 - Methodology (349-444). Boston, MA: Allyn \& Bacon.

Brotheridge, C. M., \& Grandey, A. A. (2002). Emotional labor and burnout: Comparing two perspectives of 'people work' Journal of Vocational Behavior, 60, 17-39.

Burke, P. J., \& Stets, J. (2009). Identity theory. New York: Oxford University Press.

Callister, R. R., \& Wall, J. A. Jr., (2001). Conflict across organizational boundaries: Managed care organizations versus health care providers. Journal of Applied Psychology, 86, 754-763.

Chapman, D., Uggerslev, K., Carroll, K., Piasentin, K., \& Jones, D. (2005). Applicant attraction to organizations and job choice: A meta-analytic review of the correlates of recruiting outcomes. Journal of Applied Psychology, 90, 928-944.

Cockell, J. G. (2002). Civil-military responses to security challenges in peace operations: Ten lessons from Kosovo. Global Governance, 8, 483-582.

Cohn, T. (2000). Global political economy in theory and practice. New York: Addison Wesley Longman.

Cordes, C. L., \& Dougherty, T. W. (1993). A review and an integration of research on job burnout. Academy of Management Review, 18, 621-656.

Cross, R., \& Cummings, J. N. (2004). Tie and network correlates of individual performance in knowledge-intensive work. Academy of Management Journal, 47, 928-937.

Dalal, A., \& Singh, R. (1986). An integration theoretical analysis of expected job attractiveness and satisfaction. International Journal of Psychology, 21, 555-564.

Demerouti, E., Bakker, A., Nachreiner, F., \& Schaufeli, W. (2001). The job demands-resources model of burnout. Journal of Applied Psychology, 86, 499-512.

Doucet, L., \& Jehn, K. A. (1997). Analyzing harsh words in a sensitive setting: American expatriates in communist China. Journal of Organizational Behavior, 18, 559-582. 
Douglas, S., \& Dubois, B. (1977). Looking at the cultural environment for international marketing opportunities. Columbia Journal of World Business, 12, 47-56.

Dubinskas, F. A. (1992). Culture and conflict: The cultural roots of discord. In D. M. Kolb, \& J. M. Bartunek (Eds.), Hidden conflict in organizations (187-208). Newbury Park, CA: Sage.

Duffey, T. (2001). Cultural issues in contemporary peacekeeping. International Peacekeeping, 7, 142-168.

Edmondson, A. (1999). A safe harbor: Social psychological conditions enabling boundary spanning in work teams. In R. Wageman, M. A. Neale, \& E. A. Mannix (Eds.), Research on managing groups and teams (2, 179-199). Greenwich, CT: JAI Press.

Edwards, J. R., \& Rothbard, N. P. (2000). Mechanisms linking work and family: Clarifying the relationship between work and family constructs. Academy of Management Review, 25, 178-199.

Erez, M., \& Gati, E. (2004). A dynamic multi-level model of culture: From the micro-level of the individual to the macro level of a global culture. Applied Psychology: An International Review, 53, 583-598. pdf.

Fabrigar, L. R., Wegener, D. T., MacCallum, R. C., \& Strahan, E. J. (1999). Evaluating the use of exploratory factor analysis in psychological research. Psychological Methods, 4, 272-299.

Flint, E. (2001). Civil affairs: Soldiers building bridges. In D. S. Gordon, \& F. H. Toase (Eds.), Aspects of peacekeeping (231252). Portland, OR: Frank Cass \& Co.

Friedman, R., \& Polodny, J. (1992). Differentiation of boundary spanning roles: Labor negotiations and implications for role conflict. Administrative Science Quarterly, 37, 28-47.

Gaertner, S. L., Dovidio, J. F., Rust, M. C., Nier, J. A., Banker, B. S., \& Ward, C. M., et al. (1999). Reducing intergroup bias: Elements of intergroup cooperation. Journal of Personality and Social Psychology, 76, 388-402.

Gelfand, M. J., Erez, M., \& Aycan, Z. (2007). Cross-cultural organizational behavior. Annual Review of Psychology, $58,479-514$.

Greenhaus, J., \& Beutell, N. (1985). Sources and conflict between work and family roles. Academy of Management Review, 10, 76-88.

Gibson, C. B., \& Gibbs, J. L. (2006). Unpacking the concept of virtuality: The effects of geographic dispersion, electronic dependence, dynamic structure, and national diversity on team innovation. Administrative Science Quarterly, 51, 451-495.

Harinck, F., De Dreu, K. W., \& Van Vianen, A. E. M. (2000). The impact of conflict issues on fixed-pie perceptions, problem solving, and integrative outcomes in negotiation. Organizational Behavior and Human Decision Processes, 81, $329-358$.

Haunschild, P. R., \& Miner, A. S. (1997). Modes of interorganizational imitation: The effects of outcome salience and uncertainty. Administrative Science Quarterly, 42, 472-500.

Heckman, J. (1979). Sample selection bias as a specification error. Econometrica, 47, 153-161.

Hewstone, M., \& Brown, R. (1986). Contact is not enough: An intergroup perspective on the contact hypothesis. In M. Hewstone, \& R. Brown (Eds.), Contact and conflict in intergroup encounters (1-44). Oxford: Blackwell.

Hochschild, A. R. (1983). The managed heart: Commercialization of human feeling. Berkeley, CA: University of California Press.

Hofstede, G. (2001). Culture's consequences: Comparing values, behaviors, institutions, and organizations across nations. Thousand Oaks, CA: Sage.

Hu, L., \& Bentler, P. M. (1999). Cutoff criteria for fit indexes in covariance structure analysis: Conventional criteria versus new alternatives. Structural Equations Modeling, 6, 1-55.

Huberman, M. A., \& Miles, M. B. (1985). Assessing local causality in qualitative research. In D. N. Berg, \& K. K. Smith (Eds.), Exploring clinical methods for social research 351-381. Thousand Oaks, CA: Sage Publications.

Huff, A. S. (1990). Mapping strategic thought. Chichester, NY: John Wiley and Sons.

Jackson, C. L., Colquitt, J. A., Wesson, M. J., \& Zapata-Phelan, C. P. (2006). Psychological collectivism: A measurement validation and linkage to group member performance. Journal of Applied Psychology, 91, 884-899.

Jap, S. D. (2001). "Pie sharing" in complex collaboration contexts. Journal of Marketing Research, 38, 86-99.

Jehn, K. A., \& Bezrukova, K. (2004). A field study of group diversity, workgroup context, and performance. Journal of Organizational Behavior, 25, 703-729.

Jehn, K. A., \& Mannix, E. A. (2001). The dynamic nature of conflict: A longitudinal study of intragroup conflict and group performance. The Academy of Management Journal, 44, 238-251.

Jehn, K. A., \& Werner, O. (1993). Hapax Legomenon II: Theory, a thesaurus, and word frequency. Cultural Anthropology Method, $5,8-10$.

Jennings, E. T., Jr., \& Ewalt, J. G. (1998). Interorganizational coordination, administrative consolidation, and policy performance. Public Administration Review, 58, 417-428.

Johnson, J. L., \& O’Leary-Kelly, A. M. (2003). The effects of psychological contract breach and organizational cynicism: Not all social exchange violations are created equal. Journal of Organizational Behavior, 24, 627-647.

Kabanoff, B. (1996). Computers can read as well as count: How computer-aided text analysis can benefit organisational research. In C. Cooper, \& D. M. Rousseau (Eds.), Trends in organizational behavior (3, 1-21). Hoboken, NJ: John Wiley \& Sons Inc. 
Kabanoff, B. (1997). Computers can read as well as count: Computer-aided text analysis in organizational research. Journal of Organizational Behavior, 18, 507-511.

Katz, D., \& Kahn, R. L. (1978). The social psychology of organization. New York: Wiley.

Kellogg, K. C., Orlikowski, W. J., \& Yates, J. (2006). Life in the trading zone: Structuring coordination across boundaries in postbureaucratic organizations. Organization Science, 17, 22-44.

Keenan, P. A., \& Carnevale, P. J. (1989). Positive effects of within-group cooperation on between-group negotiation. Journal of Applied Social Psychology, 19, 977-992.

Kline, R. B. (1998). Principles and practice of structural equation modeling. NY: Guilford Press.

Kunreuther, H. \& Useem M. (Eds.), (2009). Learning from catastrophes: Strategies for reaction and response. Philadelphia, PA: Wharton School Publishing.

LaBianca, G., Brass, D. J., \& Gray, B. (1998). Social networks and perceptions of intergroup conflict: The role of negative relationships and third parties. Academy of Management Journal, 41, 55-67.

Last, D. (2000). Organizing for effective peacebuilding. International Peacekeeping, 7, 8-96.

Liebeskind, J. P., Oliver, A. L., Zucker, L., \& Brewer, M. (1996). Social networks, learning, and flexibility: Sourcing scientific knowledge in new biotechnology firms. Organization Science, 7, 428-444.

Luo, Y. (2005). How important are shared perceptions of procedural justice in cooperative alliances? Academy of Management Journal, 48, 695-709.

Lysonski, S., Singer, A., \& Wilemon, D. (1988). Coping with environmental uncertainty and boundary spanning. The Journal of Business \& Industrial Marketing, 3, 5-17.

Marrone, J. A., Tesluk, P. E., \& Carson, J. B. (2007). A multilevel investigation of antecedents and consequences of team member boundary-spanning behavior. Academy of Management Journal, 50, 1423-1430.

Molinsky, A. L. (2007). Cross-cultural code-switching: The psychological challenges of adapting behavior in foreign cultural interactions. Academy of Management Review, 32, 622-640.

Mullin, B. A., \& Hogg, M. A. (1998). Dimensions of subjective uncertainty in social identification and minimal intergroup discrimination. British Journal of Social Psychology, 37, 345-365.

Mulroy, E., \& Tamburo, M. (2004). Nonprofit organizations and welfare-to-work: Environmental turbulence and organizational change. Administration in Social Work, 28, 111-135.

Muthén, L. K., \& Muthén, B. O. (1998-2007). Mplus User’s Guide (5th ed.). Los Angeles, CA: Muthén \& Muthén.

Oliver, A. L., \& Liebeskind, J. P. (1998). Three levels of networking for sourcing intellectual capital in biotechnology: Implications for studying interorganizational networks. International Studies of Management \& Organization, $27,76-103$.

Pettigrew, T. F. (1998). Intergroup contact theory. Annual Review of Psychology, 49, 65-85.

Pettigrew, T. F., \& Tropp, L. R. (2006). A meta-analytic test of intergroup contact theory. Journal of Personality and Social Psychology, 90, 751-783.

Perrone, V., Zaheer, A., \& McEvily, B. (2003). Free to be trusted? Organizational constraints on trust in boundary spanners. Organization Science, 14, 422-439.

Pfeffer, G., \& Salancik, G. (2003). The external control of organizations: A resource dependence perspective. Stanford, CA: Stanford University Press.

Podsakoff, P. M., MacKenzie, S. B., Lee, J., \& Podsakoff, N. P. (2003). Common method biases in behavioral research: A critical review of the literature and recommended remedies. Journal of Applied Psychology, 88, 879-903.

Pratto, F., \& John, O. P. (1991). Automatic vigilance: The attention-grabbing power of negative social information. Journal of Personality and Social Psychology, 61, 380-391.

Proudford, K., \& Smith, K. (2003). Group membership salience and the movement of conflict. Group \& Organization Management, 28, 18-44.

Ramarajan, L., Bezrukova, K., Jehn, K. A., Euwema, M., \& Kop, N. (2004). Relationship between peacekeepers and NGO workers: The role of training and conflict management styles in international peacekeeping. International Journal of Conflict Management, 15, 167-191.

Reid, S. A., \& Hogg, M. A. (2005). Uncertainty reduction, self-enhancement, and ingroup identification. Personality and Social Psychology Bulletin, 31, 804-817.

Report of the Panel on United Nations Peacekeeping Operations. (2000). Document of the Secretary General. A/55/305-S/2000/ 809.

Richter, A. W., West, M., Van Dick, R., \& Dawson, J. F. (2006). Boundary spanners' identification, intergroup contact, and effective intergroup relations. Academy of Management Journal, 49, 1252-1269.

Romero, A. J., Carvajal, S. C., Valle, F., \& Orduna, M. (2007). Adolescent bicultural stress and its impact on mental well-being among Latinos, Asian Americans, and European Americans. Journal of Community Psychology, 35, 519-534.

Roth, P. L. (1994). Missing data: A conceptual review for applied psychologists. Personnel Psychology, 47, 537-560.

Roth, P. L., \& BeVier, C. A. (1998). Response rates in HRM/OB survey research: Norms and correlates. Journal of Management, 24, 97-117. 
Rothbard, N. P. (2001). Enriching or depleting? The dynamics of engagement in work and family roles. Administrative Science Quarterly, 46, 655-684.

Rynes, S. L., \& Miller, H. E. (1983). Recruiter and job influences on candidates for employment. Journal of Applied Psychology, 68, 147-154.

Rynes, S. L., \& Barber, A. E. (1990). Applicant attraction strategies: An organizational perspective. Academy of Management Review, 15, 286-310.

Saks, A. M. (1989). An examination of the combined effects of realistic job previews, job attractiveness and recruiter affect on job acceptance decisions. Applied Psychology: An International Review, 38, 145-163.

Saks, A. M., Wiesner, W. H., \& Summers, R. J. (1996). Effects of job previews and compensation policy on applicant attraction and job choice. Journal of Vocational Behavior, 49, 68-85.

Schwartz, S. H. (1994). Beyond individualism/collectivism: New cultural dimensions of values. In U. Kim, H. C. Triandis, C. Kagitcibasi, S. Choi, \& G. Yoon (Eds.), Individualism and collectivism: Theory, method, and applications (85-119). Thousand Oaks, CA: Sage.

Schwartz, S. (1999). A theory of cultural values and some implications for work. Applied Psychology: An International Review, 48, 23-47.

Sherif, M., \& Sherif, C. W. (1969). Social psychology. New York, NY: Harper and Row.

Singh, J. (2005). Collaborative networks as determinants of knowledge diffusion patterns. Management Science, 51, 756-770.

Singh, J., Goolsby, J., \& Rhoads, G. (1994). Behavioral and psychological consequences of boundary spanning burnout for customer service representatives. Journal of Marketing Research, 31, 558-569.

Sion, L. (2008). Dutch peacekeepers and host environments in the Balkans: An ethnographic perspective. International Peacekeeping, 15, 201-213.

Smith, K. K. (1989). The movement of conflict in organizations: The joint dynamics of splitting and triangulation. Administrative Science Quarterly, 34, 1-20.

Switzer, F. S. III., Roth, P. L., \& Switzer, D. M. (1998). Systematic data loss in HRM settings: A Monte Carlo analysis. Journal of Management, 24, 763-779.

Takeuchi, R., Yun, S., \& Tesluk, P. E. (2002). An examination of crossover and spillover effects of spousal and expatriate crosscultural adjustment on expatriate outcomes. Journal of Applied Psychology, 87, 655-666.

Tushman, M. L. (1977). Special boundary roles in the innovation process. Administrative Science Quarterly, 22 , 587-606.

Tushman, M. L., \& Katz, R. (1980). External communication and project performance: An investigation into the role of gatekeepers. Management Science, 26, 1071-1085.

Tushman, M. L., \& Scanlan, T. J. (1981). Characteristics and external orientations of boundary spanning individuals. Academy of Management Journal, 24, 83-98.

Van Vianen, A. E. M., De Pater, I. E., Kristof-Brown, A. L., \& Johnson, E. C. (2004). Fitting in: Surface- and deep-level cultural difference and expatriates' adjustment. Academy of Management Journal, 47, 697-709.

Walker, W. R., Vogl, R. J., \& Thompson, C. P. (1997). Autobiographical memory: Unpleasantness fades faster than pleasantness over time. Applied Cognitive Psychology, 11, 399-413.

Walker, W. R., Skowronski, v., \& Thompson, C. P. (2003). Life is pleasant-and memory helps to keep it that way. Review of General Psychology, 7, 203-210.

Wall, J. A., \& Callister, R. R. (1995). Conflict and its management. Journal of Management, 21, 515-558.

Weiss, T. G. (1999). Military civil interactions: Intervening in humanitarian crises. Lanham, MD: Rowman \& Littlefield Publishers.

Williams, M. (2007). Building genuine trust through interpersonal emotion management: A threat regulation model of trust and collaboration across boundaries. Academy of Management Review, 32, 595-621. 